http://jmscr.igmpublication.org/home/ ISSN (e)-2347-176x ISSN (p) 2455-0450

crossref DOI: https://dx.doi.org/10.18535/jmscr/v9i1.09

\author{
Journal Of Medical Science And Clinical Research \\ IGM Publication \\ An Official Publication of IGM Publication
}

\title{
Anaesthetic Management of a Patient with Hereditary Spherocytosis and Cholelithiasis for Splenectomy and open Cholecystectomy under General Anaesthesia - A Case Report
}

\author{
Authors \\ Dr Arun B V1 $\mathbf{1}^{\text {, Dr Lailu Mathews }}{ }^{2}$
}

${ }^{1}$ Final year postgraduate, Department of Anesthesiology, Chettinad Hospital and Research Institute

${ }^{2}$ Professor, Department of Anesthesiology, Chettinad Hospital and Research Institute

\begin{abstract}
Hereditary spherocytosis (HS) is an autosomal dominant type of congenital haemolytic anaemia. The spherocytes are susceptible to osmotic lysis resulting in anaemia, jaundice, splenomegaly, cholelithiasis and altered the liver function. The management of hereditary spherocytosis is largely dependent on the severity of anaemia and degree of haemolysis. The anaesthetic management of a patient with HS and cholelithiasis for splenectomy and open cholecystectomy is discussed here.

Keywords: Hereditary Spherocytosis; Haemolysis; Splenomegaly; Splenectomy.
\end{abstract}

\section{Introduction}

Hereditary spherocytosis (HS) is an extremely rare autosomal dominant familial haemolytic disorder with marked heterogenecity of clinical features ranging from asymptomatic condition to fulminant haemolytic anaemia. The estimated prevalence in the caucasian population ranges from $1: 2000$ to $1: 5000{ }^{(1)}$ In $80 \%$ of cases the inheritance of HS is autosomal dominant and in remaining as recessive genes or sporadic type. ${ }^{(2)}$ It is characterized by a deficiency of ankyrin or spectrin (transmembrane proteins) that link the bilayer of red cells to the membrane skeleton. Abnormal spherocytes are trapped and destroyed in the spleen resulting in haemolysis. The spherocytes are susceptible to osmotic lysis resulting in anaemia, jaundice, splenomegaly, cholelithiasis and alters the liver function which affects metabolism of anaesthetic agents in these patients. $^{(3)}$

\section{Case Report}

A 30-year-old lady presented with complaints of right hypochondrial abdominal pain, intermittent low grade fever and yellowish discoloration of eyes since 1 week. She was diagnosed to have hereditary spherocytosis 8 years ago with no history of bleeding manifestations.

On general examination, the patient was thin built with height of $153 \mathrm{~cm}$ \&weight of $40 \mathrm{kgs}$. Pulse rate - 92/min; blood pressure - 100/70 $\mathrm{mmHg}$ and respiratory rate $-16 / \mathrm{min}$. Patient was afebrile, pale and icteric with no lymphadenopathy. On auscultation breath sounds and heart sounds were normal. Abdominal examination revealed grade 3 splenomegaly of $6 \mathrm{~cm} \times 8 \mathrm{~cm}$ with tenderness. Airway examination - Malampatti class-II, Mouth opening $>3 \mathrm{~cm}$ with adequate neck movements. On admission blood investigations done Haemoglobin - 3.4g/dl; Platelet count 1,83,000cells/cumm; Total bilirubin $-3.60 \mathrm{~g} / \mathrm{gl}$; 
Direct bilirubin - 0.806g/dl; AST - 45 IU/L; ALT - 95 IU/L; Random blood sugar - 107; Urea -16.8; Creatinine -1.0; PT - \{Control - 11.03, Test -13$\}$ ; INR - 1.18; $\mathrm{Na}^{+} 136 ; \mathrm{K}^{+} 3.9$; Bleeding time - 2 minutes; clotting time: 5 minutes; HIV nonreactive; HBs Ag\& HCV - Negative; Direct and indirect \& Coombs test - negative \& Reticulocyte count $-19.80 \%$.

Peripheral smear - spherocytosis, erythropenia\& normocytic normochromic RBC's. Osmotic fragility of incubated blood did not show marked increase.

USG abdomen - moderate splenomegaly, cholelithiasis with GB wall oedema. ECG \& chest X-ray revealed no abnormality \& all other labs were within normal limits.

Vaccination against pneumococci and haemophilus was given 14 days prior to surgery.

The patient was transfused with 4 units of packed red blood cells (PRBCs) preoperatively (over a period of 8 days). Patient had Haemoglobin $7.9 \mathrm{~g} / \mathrm{dl}$; platelet count $-1,28,000$ cells/cumm; INR -1.12 on the day of surgery.

Patient was assessed under ASA grade 2 and advised premedication of Tab. Rantidine $150 \mathrm{mg}$ on the night prior to surgery and on the morning of surgery. After shifting the patient to OT, adequate IV access was secured (18G). Standard monitoring of 5 lead ECG, non-invasive blood pressure and pulse oximeter was instituted. Preoperative heart rate of $70 / \mathrm{min}$, Blood pressure 100/60 $\mathrm{mmHg}$ and $\mathrm{SpO}_{2} 100 \%$ in room air.

General anaesthesia with epidural analgesia was planned. Epidural catheter was placed in $\mathrm{T}_{12}-$ $\mathrm{L}_{1}$ intervertebral disc space under all aseptic precautions and test dose of $3 \mathrm{ml}$ of $2 \%$ lignocaine with adrenaline was given.

Premedication given withInj. Glycopyrrolate $0.2 \mathrm{mg}$ iv, Inj. Midazolam $1 \mathrm{mg}$ iv and Inj. Fentanyl 60mcg iv. Anaesthesia was induced with Inj. Propofol $60 \mathrm{mg}$ iv following which endotracheal intubation was facilitated with Inj. Atracurium $25 \mathrm{mg}$ iv and a cuffed portex ET tube of size $7 \mathrm{~mm}$ ID was placed. After securing the ET tube, a ryles tube was inserted.
Heart rate, NIBP, End tidal $\mathrm{CO}_{2}, \mathrm{SpO}_{2}$, temperature and hourly urine output were monitored throughout surgery. Anaesthesia was maintained with $\mathrm{O}_{2}$ : Air: Isoflurane (50:50:0.8) \& intermittent doses of Inj. Atracurium $5 \mathrm{mg}$ iv. Epidural bolus of $0.125 \%$ bupivacaine $-6 \mathrm{ml}$ was given 2 hours after start of surgery, followed by epidural infusion - $0.0625 \%$ bupivacaine with $2 \mathrm{mcg} / \mathrm{kg}$ fentanyl at the rate of $6 \mathrm{ml} /$ hour till the end of surgery. Intraoperative fluid management was done with crystalloids- $2000 \mathrm{ml}$ and 2 units of PRBC's after clamping the splenic vessels. (weight of the spleen removed measured - 1100g). The perioperative goals were to avoid hypoxia, hypothermia and metabolic acidosis. Total blood loss was $1200 \mathrm{ml}$ and urine output $-1150 \mathrm{ml}$. The intra-operative period was uneventful and arterial blood gas analysis done showed $\mathrm{pH}-7.311 ; \mathrm{pCO}_{2}$ - 44.6; Lac - 2.0; $\mathrm{HCO}_{3}$ - 21; $\mathrm{Hb}$ 11.6.Neuromuscular blockade was reversed with Inj. neostigmine $1 \mathrm{mg}+$ Inj. glycopyrrolate $0.2 \mathrm{mg}$ IV. The trachea was extubated after thorough oropharyngeal suctioning and shifted to post anaesthesia care unit for further observation. Total duration of surgery was 4 hours.

Epidural infusion was continued in the post-op period for analgesia. Chest physiotherapy \& incentive spirometry were started. On postoperative day 1, patient had two febrile episodes (Temp - $101^{0} \mathrm{~F} \quad \& \quad 100.8^{0} \mathrm{~F}$ )and blood investigations done showed TC 21,500cells/cumm; $\mathrm{Hb}-13.3 \mathrm{~g} / \mathrm{dl}$; platelet count $1,28,000$ cells/cumm. Antibiotic cover was escalated with addition of ceftriaxone \& vancomycin (in view of risk of post splenectomy sepsis), following which she improved symptomatically and remained afebrile. Epidural catheter was removed on post op day -2 , after giving bolus dose of Inj.bupivacaine $(0.125 \%)$ $5 \mathrm{cc}$. She was hemodynamically stable and shifted to ward on post-operative day 4 .

\section{Discussion}

Hereditary spherocytosis is the most common cause of inherited haemolytic anaemia in North 
America, but comparatively rare in Asians. As mentioned above it occurs due to an intrinsic genetic defect of RBC membrane proteins, which are major components of the cytoskeleton for maintaining shape of RBC.

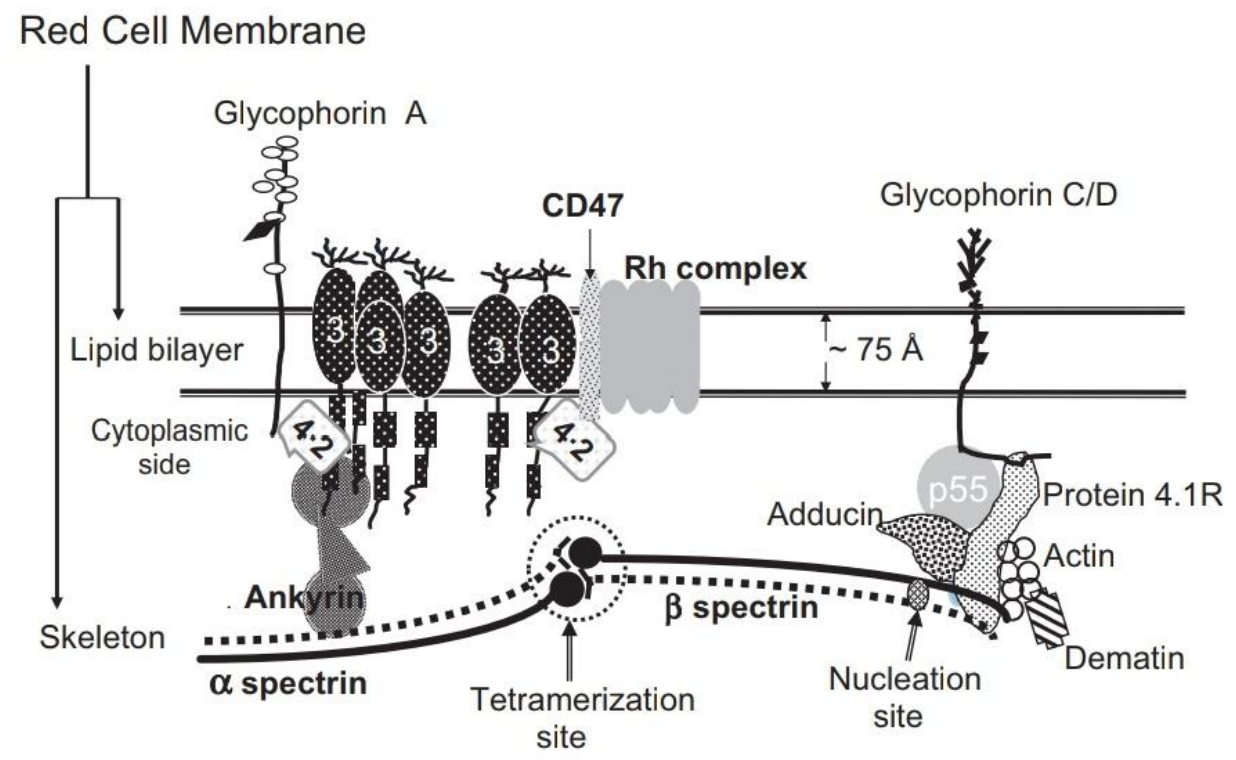

Fig 1 Schematic representation of the structural organization of the red cell cytoskeleton

Qualitative or quantitative abnormalities in these proteins causes the red cells to become spheroidal and the spleen targets the abnormal shaped RBC's but their passage into sinusoids is difficult due to spherical shape and gets phagocytosed resulting in extravascular haemolysis. ${ }^{(4)}$ In chronic cases or other concomitant illness it causes haemolytic crisis leading to anaemia, hypoxia, splenomegaly. ${ }^{(4)}$ Direct / indirect bilirubin accumulates in gall bladder to form gallstones, altering liver function and causing hepatomegaly. Splenomegaly is usually mild to moderate, the size of spleen per se is not an indication for splenectomy. Pigmented gallstones are seen in more than $50 \%$ cases. Incidence increases with severity of hemolysis and with age. Complications include cholelithiasis, aplastic anemia (most common after parvovirus B19 infection), haemolytic crisis during inter-current infection, megaloblastic crisis - during folic acid deficiency. ${ }^{(6)}$

Laboratory diagnosis mainly involves peripheral blood smear, MCV, MCHC \& reticulocyte count. The presence of spherocytes is confirmed by an osmotic fragility test the sensitivity of which varies from 48 to $95 \%$ although this maybe increased to $99 \%$ by glycerol lysis test. ${ }^{(5)}$

Table 2 Classification of hereditary spherocytosis and indications for splenectomy ${ }^{(7)}$

\begin{tabular}{|c|c|c|c|c|}
\hline Classification & Trait & Mild & Moderate & Severe \\
\hline Haemoglobin $(\mathrm{g} / \mathrm{dl})$ & Normal & $11-15$ & $8-12$ & $6-8$ \\
\hline Reticulocyte count \% & Normal $(<3 \%)$ & $3-6$ & $>6$ & $>10$ \\
\hline Bilirubin (lmol/l) & $<17$ & $17-34$ & $>34$ & $>51$ \\
\hline $\begin{array}{l}\text { Spectrin* } \\
\text { erythrocyte } \\
(\% \text { of normal })\end{array}$ & 100 & $80-100$ & $50-80$ & $40-60$ \\
\hline Splenectomy & Not required & $\begin{array}{c}\text { Usually not necessary } \\
\text { during childhood } \\
\text { and adolescence }\end{array}$ & $\begin{array}{l}\text { Necessary during } \\
\text { school } \\
\text { age before puberty }\end{array}$ & $\begin{array}{c}\text { Necessary - delay } \\
\text { until } \\
6 \text { years if possible }\end{array}$ \\
\hline
\end{tabular}


Management of HS mainly involves surgical treatment - splenectomy, however folate treatment may be considered in patients with severe haemolysis. Splenectomy is usually followed by cessation of haemolysis and clearance of jaundice. Its indicated in all patients to prevent haemolytic crisis and gallstone formation, except in those who are well compensated and asymptomatic. If gallstones are present, cholecystectomy is done concomitantly.

Anaesthetic management of HS involves presplenectomy, splenectomy and post splenectomy care. The major pre-anaesthetic concerns are correction of anaemia, supplementation of folate to prevent megaloblastic crisis and immunization with $H$. influenza and pneumococcal vaccines. Intra-operatively adequate hydration to prevent stasis, avoidance of hepatotoxic drugs, prevention of hypoxia, acidosis assessed by ABG, hypothermia prevention by administering warm fluids and proper room temperature and early replacement of blood loss with PRBCs- FFP transfusion. Postoperatively goals are oxygen supplementation, antibiotics, fluid and effective pain management.

Anemia should be corrected pre-operatively before major surgery. Recommended peri-op management include erythrocyte transfusion, aggressive hydration, avoidance of hypoxia, hypothermia and acidosis. Intraoperatively blood loss should be replaced when necessary and normal body temperature to be maintained to minimize vasoconstriction and associated circulatory stasis. Other goals include providing adequate analgesia to minimize stress, avoiding hepatotoxic drugs to maintain hepatic blood flow and $\mathrm{ABG}$ measurements to maintain acid base balance. . $^{(1,2,3)}$

Epidural anesthesia was chosen in our patient primarily because of the potential deterioration in liver function and liver blood flow that may occur with general anesthesia alone. Regional anesthesia preserves liver blood flow as long as normotension is maintained and also provides excellent intra-op / post-op analgesia. All volatile agents decrease liver blood flow, the decrease is minimum with isoflurane and hence it's the preferred volatile anaesthetic agent in such condition. ${ }^{(1,2)}$ Post splenectomy the risk of life threatening sepsis due to encapsulated organisms are high, thus close monitoring through repeat Complete blood count, RFT, chest X-ray is needed during the post-op period.

\section{Conclusion}

Vigilant intraoperative hemodynamic and temperature monitoring with appropriate measures to avoid acidosis, hypoxia and hypotension improves surgical outcome and recovery.

\section{References}

1. Anuradha M, Sonal M, Rochana B et al.,Anesthetic considerations for patient of hereditary spherocytosis for splenectomy and cholecystectomy: A case report. Indian Journal of Basic and Applied Medical Research 2014;4(1):295-297.

2. Sonal SK, Widya ST, Syed MK et al., Anesthetic management of a case with hereditary spherocytosis for splenectomy and open cholecystectomy. Medical journal of Dr. D.Y.Patil University 2016; 9(2):267-270.

3. Sidhesh B, Vilas G, Merlyn D - Anesthetic management of patient with hereditary spherocytosis for laparoscopic cholecystectomy and splenectomy. Saudi Journal of Anesthesia 2012;6(4):438-439.

4. Kalpana K, Sunetra D, Shirish T Anaesthetic management of a child with hereditary spherocytosis for splenectomy. EC Anaesthesia 2019; 5:14-19.

5. Bolton-Maggs PH, Stevens RF, Dodd NJ, Lamont G, Tittensor P, King MJ, et al., Guidelines for the diagnosis and management of hereditary spherocytosis. British Journal of Haematology 2004; 126:455-74. 
6. Olga C - old and new insights into the diagnosis of hereditary spherocytosis. Ann Transl Med 2018; 6(17):339.

7. Eber SW, Armbrust R, Schröter W. Variable clinical severity of hereditary spherocytosis: relation to erythrocyticspectrin concentration, osmotic fragility, and autohemolysis. J Pediatr 1990;117(3):409-416. 